\title{
VEGI174 protein and its functional domain peptides exert antitumour effects on renal cell carcinoma
}

\author{
QIANG ZHAO $^{1 *}$, BAOAN HONG $^{2 *}$, TIEZHU LIU ${ }^{3 *}$, YONGPENG JI ${ }^{1}$, \\ XINXIN TANG ${ }^{1}, \mathrm{KAN} \mathrm{GONG}^{2}, \mathrm{LIN} \mathrm{YE}^{4}$, YONG YANG $^{1}$ and NING ZHANG ${ }^{1}$ \\ ${ }^{1}$ Department of Urology, Beijing Institute for Cancer Research, Beijing Cancer Hospital, Beijing 100142;
Department of Urology, Peking University First Hospital, Institute of Urology, Peking University, Beijing 100034;
${ }^{3}$ Department of Urology, Daqing Oilfield General Hospital, Daqing, Heilongiiang 163001, P.R. China;
${ }^{4}$ Metastasis and Angiogenesis Research Group, Cardiff University School of Medicine, Cardiff CF14 4XN, UK
}

Received June 12, 2018; Accepted October 24, 2018

DOI: $10.3892 /$ ijo.2018.4632

\begin{abstract}
Vascular endothelial growth inhibitor (VEGI) has been identified as an anti-angiogenic cytokine. However, the effects of VEGI174 protein, and its functional domain peptides V7 and V8, on renal cell carcinoma (RCC) remain unknown. In the present study, the protein and peptides were biosynthesised as experimental agents. The A498 and 786-O RCC cell lines, and an established mouse xenograft model, were separately treated with VEGI174, V7 or V8. Cellular functions, including proliferation, migration and invasion, were subsequently detected. Cell migration and invasion were monitored using the xCELLigence system. Furthermore, tumour growth and mouse behaviours, including mobility, appetite and body weight, were assessed. The results demonstrated that VEGI174, V7 and V8 inhibited the proliferation, migration and invasion of A498 and 786-O cell lines when administered at concentrations of 1 and $100 \mathrm{pM}, 10 \mathrm{nM}$ and $1 \mu \mathrm{M}$. The inhibitory effects exhibited dose- and time-dependent antitumour activity. Furthermore, VEGI174, V7 and V8 inhibited tumour growth in A498 and 786-O xenograft mice. In the A498 xenografts, the tumour growth inhibition (TGI) rates in the VEGI174-, V7- and V8-treated groups were 71, 20 and $31 \%$, respectively. In the 786-O xenografts, the TGI rates in the VEGI174-, V7- and V8-treated groups were 34, 26 and $31 \%$, respectively. There was no significant loss in body weight and no cases of mortality were observed for all treated
\end{abstract}

Correspondence to: Professor Ning Zhang or Professor Yong Yang, Department of Urology, Beijing Institute for Cancer Research, Beijing Cancer Hospital, 52 Fucheng Road, Haidian, Beijing 100142, P.R. China

E-mail: niru7429@126.com

E-mail: doctormed@126.com

*Contributed equally

Key words: renal cell carcinoma, vascular endothelial growth inhibitor, peptide, in vitro, in vivo mice. In conclusion, VEGI174, V7 and V8 exhibited potential antitumour effects and were well tolerated in vivo. V7 and V8, as functional domain peptides of the VEGI174 protein, may be studied for the future treatment of RCC.

\section{Introduction}

Renal cell carcinoma (RCC) is a common malignancy of the genitourinary system that accounts for $5 \%$ of new cancer cases in males and $3 \%$ in females worldwide; RCC was responsible for 14,240 cases of mortality in the United States of America in 2016 (1). The majority of patients with localised RCC are effectively treated with radical nephrectomy, and 25-30\% of these patients ultimately present with disseminated disease. Furthermore, nearly a third of patients who undergo surgery will experience recurrence or progression (2). The prognosis of metastatic RCC is poor, with a median overall survival of 12 months and a 5-year survival rate of $<10 \%$ (3).

Over the past decade, steps have been made towards developing targeted therapies for patients with advanced RCC $(4,5)$, which have increased the therapeutic response rate and improved survival outcomes. Tyrosine kinase inhibitors targeting vascular endothelial growth factor (VEGF) receptors are considered first-line therapies for RCC (6-8). In addition, RCC appears to be particularly sensitive to strategies that target tumour-associated angiogenesis; however, complete and long-term responses to the current targeted therapies are rare, and the cancer usually progresses (9). Notably, RCC is not a single disease but is a process associated with complex and heterogeneous tumourigenesis, which may confer resistance to targeted therapies $(10,11)$. Therefore, it is essential that novel therapeutic strategies or targets be explored in future research.

Vascular endothelial growth inhibitor (VEGI) is a member of the tumour necrosis factor (TNF) superfamily, which has been identified as an anti-angiogenic cytokine $(12,13)$. It is located on human chromosome 9q32 (Gene ID: 9966). The full-length VEGI gene is $\sim 17 \mathrm{~kb}$, and consists of four exons and three introns. Three alternatively spliced isoforms, VEGI174, VEGI192 and VEGI251, have been documented and share 151 common C-terminal amino acids (AAs) with different $\mathrm{N}$-terminal regions. The initially reported VEGI 
protein consists of 174 AAs that can be divided into two parts: AA residues $1-25$ at the $\mathrm{N}$-terminus constitute an intracellular transmembrane domain, and AA residues 26-174 at the C-terminus form an extracellular domain (14,15). VEGI is highly expressed in kidney, bladder, prostate, lung, breast and colon tissues (16-21). Our previous studies revealed that overexpression of VEGI174 significantly inhibited RCC cell proliferation, motility, adhesion and epithelial-mesenchymal transition (EMT) in vitro and in vivo (21-24). Taken together, these previous data suggested that VEGI174 exerts inhibitory effects on RCC; therefore, it may be valuable to be further study VEGI174 with regards to RCC treatment.

As an endothelial cell-secreted cytokine, the role of VEGI174 in RCC is unclear, and whether its functional domain peptides exert the same effects on RCC has yet to be reported. The present study designed different peptide fragments based on the functional domain of the VEGI174 protein. Furthermore, the biological functions of VEGI174 and its functional domain peptides were assessed on RCC in vitro and in vivo, and how well the compounds were tolerated was investigated.

\section{Materials and methods}

Selection of effective functional domains of VEGI174. The present study was approved by the ethics committee of Beijing Institute for Cancer Research (Beijing, China). Based on the human VEGI sequence (GenBank: NC_000009.12; https://www.ncbi.nlm.nih.gov/genbank/), eight different segments (V1-V8) were designed that encode the VEGI174 functional extracellular domains (23). In our prestudies, the full-length human VEGI174 and functional domain (V1-V8) genes were respectively cloned into mammalian expression plasmid vectors ( $\mathrm{pEF} / \mathrm{His}$ TOPO TA; Invitrogen; Thermo Fisher Scientific, Inc., Waltham, MA, USA) and were then transfected into human umbilical vein endothelial cells (HUVECs; American Type Culture Collection, Manassas, VA, USA). Briefly, HUVECs (confluence, 50-60\%) were transfected with the vectors using Lipofectamine ${ }^{\circledR} 2000$ (Invitrogen; Thermo Fisher Scientific, Inc.) at $37^{\circ} \mathrm{C}$ for $10 \mathrm{~h}$; overexpression was confirmed by western blotting and reverse transcription-quantitative polymerase chain reaction. An electric cell-substrate impedance sensing measuring system (ibidi GmbH, Planegg, Germany) revealed that overexpression of VEGI174 or V1-V8 was able to inhibit the motility and adhesion of HUVEC cells $(25,26)$. Specifically, the inhibitory effects of overexpressing the V7 or V8 gene fragments were more significant (Fig. 1). Therefore, the full-length VEGI174 protein and V7 and V8 peptides were selected as target agents in the present study.

Biosynthesis of the VEGI174 protein and its domain peptides. VEGI174 protein and its domain peptides (V7 and V8) were biosynthesised and qualified by the School of Pharmaceutical Sciences, Sun Yat-Sen University (Guangzhou, China). The AA sequence of the VEGI174 protein and its domain peptides are listed in Table I.

Cell culture. The human RCC cell lines, A498 and 786-O, were provided by Sun Yat-Sen University Laboratory (Guangzhou, China). In vitro cell culture was conducted in Dulbecco's modified Eagle's medium (HyClone; GE Healthcare, Logan, UT, USA) or RPMI-1640 medium (HyClone; GE Healthcare), supplemented with $10 \%$ foetal bovine serum (FBS; Gibco; Thermo Fisher Scientific, Inc.) and $100 \mathrm{U} / \mathrm{ml}$ penicillin and streptomycin (Gibco; Thermo Fisher Scientific, Inc.). Cells were grown at $37^{\circ} \mathrm{C}$ in a humidified atmosphere containing $5 \% \mathrm{CO}_{2}$-air.

Animals. The animal studies were approved by the ethics committee of Beijing Institute for Cancer Research, and the Institutional Animal Care and Use Committee (IACUC) of Crown Bioscience (Beijing, China). Female BALB/c nude and NOD/SCID mice (n=5/group; age, 4-6 weeks; weight, 16-20 g; specific pathogen-free degree) were supplied by Beijing FuKang Bioscience (Beijing, China; Animal Certificate no. 11401300025891). Mice were maintained under the following conditions: Temperature, $18-22^{\circ} \mathrm{C}$; humidity, 50-60\%; 12-h light/dark cycle; ad libitum food/water access Procedures related to animal handling, care and treatment in this study were performed according to the guidelines approved by the IACUC of Crown Bioscience and following the guidance of the Association for Assessment and Accreditation of Laboratory Animal Care.

Cell proliferation assay. Cancer cells were harvested during the logarithmic growth phase and were counted using a Countstar automated cell counter (ALIT Life Science Co., Ltd., Shanghai, China). Cell concentration was adjusted to $5.0 \times 10^{4} / \mathrm{ml}$ in culture medium. Cell suspensions, $\sim 100 \mu \mathrm{l} /$ well, were seeded in 96-well plates (Corning Incorporated, Corning, NY, USA) and were cultured in a humidified incubator at $37^{\circ} \mathrm{C}$ under $5 \% \mathrm{CO}_{2}$ for $24 \mathrm{~h}$. Subsequently, VEGI174 and its domain peptides (V7 and V8), at various concentrations, were separately added to each well at final concentrations of 1 and $100 \mathrm{pM}, 10 \mathrm{nM}$ and $1 \mu \mathrm{M}$. Cytoactivity was detected using a Cell Counting Kit-8 assay (Dojindo Molecular Technologies, Inc., Kumamoto, Japan), according to the manufacturer's protocol, at 24, 48, 72, 96 and $120 \mathrm{~h}$.

Real-time measurement of cell migration and invasion. Cell migration and invasion were monitored using the xCELLigence system (Roche Applied Science, Penzberg, Germany) (27-29). To examine cell migration, the RCC cells were incubated in a cell invasion/migration (CIM)-plate 16 (8- $\mu \mathrm{m}$ pore size; Roche Applied Science) coated with fibronectin. The lower chambers were filled with fresh medium containing $10 \%$ FBS. The upper chambers were filled with serum-free medium, and the plate was incubated at $37^{\circ} \mathrm{C}$ in an atmosphere containing $5 \% \mathrm{CO}_{2}$. Subsequently, VEGI174 and its domain peptides (V7 and V8), at various concentrations, were separately added to each well, at final concentrations of 1 and $100 \mathrm{pM}, 10 \mathrm{nM}$ and $1 \mu \mathrm{M}$. The CIM-plate was assembled onto the Real-Time Cell Analyzer (RTCA) with dual-plate format instrument, and cell migration was assessed at 15-min intervals for 24-48 h. Data acquisition and analysis were performed using RTCA software (version 1.2; Roche Diagnostics, Basel, Switzerland).

Invasion was measured with the RTCA in the same manner as migration; however, a layer of Matrigel (BD Biosciences, Franklin Lakes, NJ, USA) was added to the upper side of the membranes. 
Table I. Amino acid sequence of VEGI174 protein (V7 peptide contains AA 81-145, V8 peptide contains AA 118-145).

Name

AA sequence

VEGI174

MRRFLSKVYS FPMRKLILFL VFPVVRQTPT QHFKNQFPAL HWEHELGLAF/50 AA
TKNRMNYTNK FLLIPESGDY FIYSQVTFRG MTSECSEIRQ AGRPNKPDSI/100 AA
TVVITKVTDS YPEPTQLLMG TKSVCEVGSN WFQPIYLGAM FSLQEGDKLM/150 AA
VNVSDISLVD YTKEDKTFFG AFLL/174 AA

${ }^{a}$ GenBank accession no. AAD08783.1. AA, amino acid; VEGI174, vascular endothelial growth inhibitor 174.

A

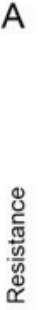

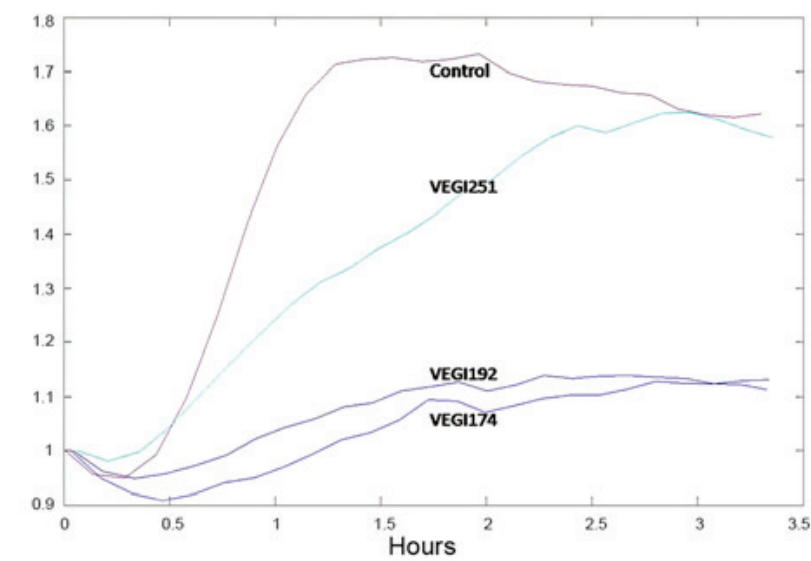

C

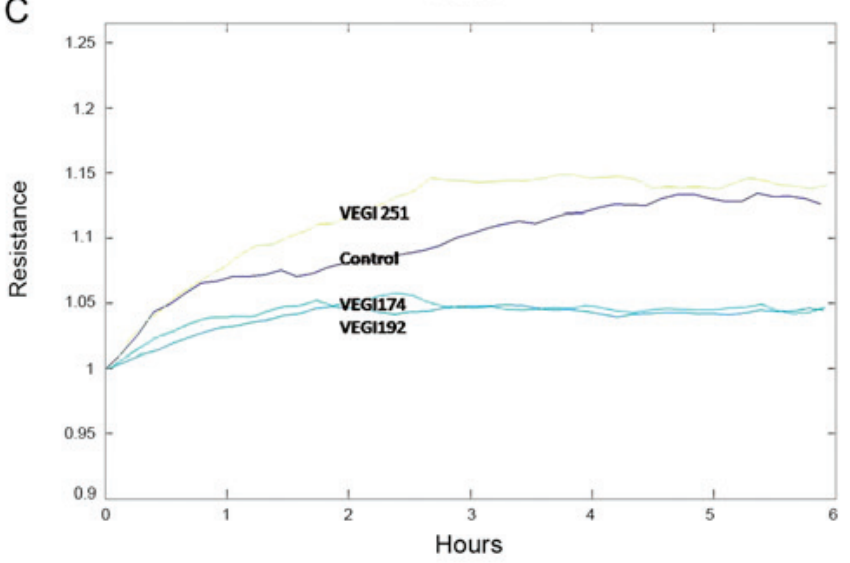

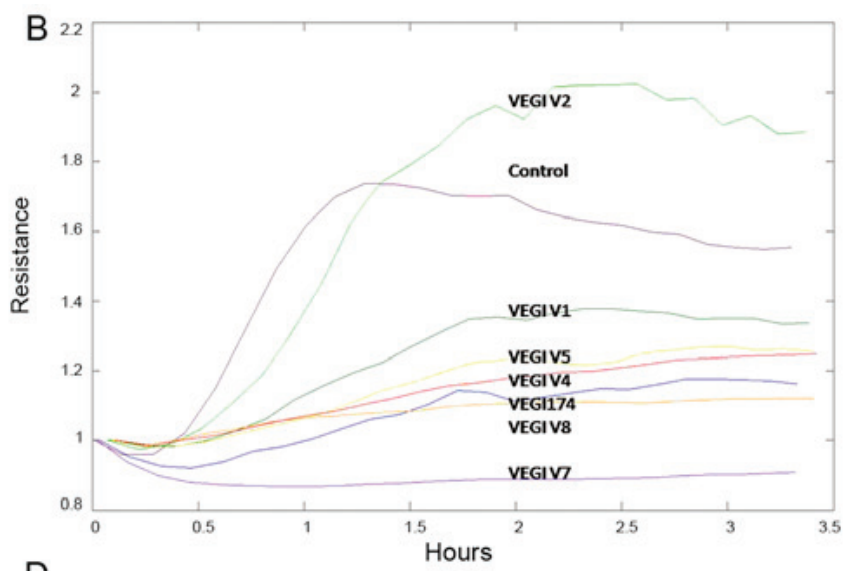

D

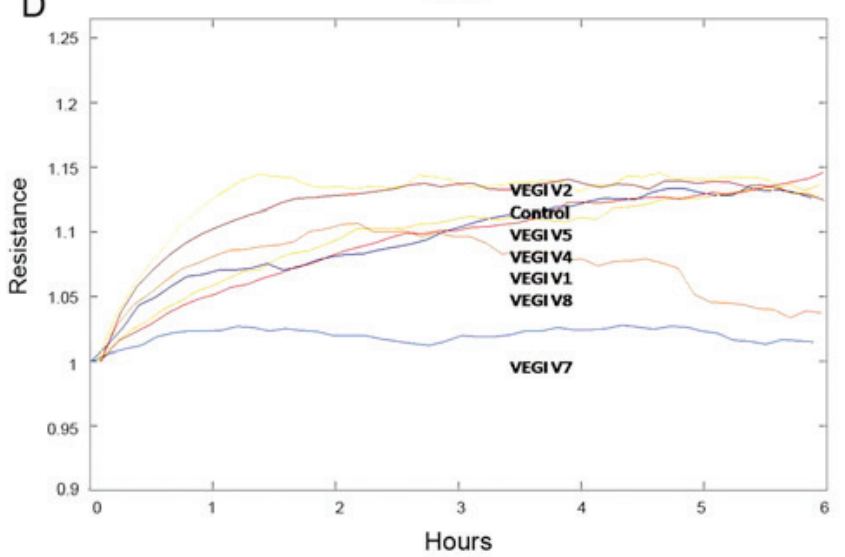

Figure 1. Cell adhesion and motility of HUVECs overexpressing full-length VEGI174, VEGI192 and VEGI251, and the VEGI174 functional fragments V1-V8, were detected using an electric cell-substrate impedance sensing cell function detector. (A and B) Overexpression of VEGI174, VEGI192, V4, V5, V7 and V8 inhibited HUVEC adhesion; V7 and V8 exhibited more potent inhibition than the other functional domain peptides. (C and D) Overexpression of VEGI174, VEGI192, V1, V4, V7 and V8 inhibited HUECV motility; V7 and V8 exhibited more potent inhibition than the other functional domain peptides. HUVECs, human umbilical vein endothelial cells; VEGI, vascular endothelial growth inhibitor.

In vivo xenograft studies. A498 and 786-O cell lines were implanted into NOD/SCID mice and BALB/c nude mice, respectively. Briefly, the mice were subcutaneously injected into the right flank with RCC cells $\left(3 \times 10^{6}\right)$ mixed with Matrigel (100 $\mu \mathrm{l})$. Tumour dimensions were measured using a Vernier caliper. Tumour sizes were calculated using the following formula: Tumour volume $\left(\mathrm{mm}^{3}\right)=\left(\right.$ length $\mathrm{x}$ width $\left.{ }^{2}\right) / 2$. When the tumours grew to $130-190 \mathrm{~mm}^{3}$ in size, the animals were randomised into an untreated control group and treatment groups ( $\mathrm{n}=5 \mathrm{mice} / \mathrm{group})$. VEGI174, V7 and V8 were administered as single agents, and PBS was used as a blank control. Mice were treated via intratumoural injections every other day and received a total of four doses (Q2Dx4; Table II). Tumour growth and behavioural data, including mobility, visual estimation of food and water consumption, and body weight alterations, were assessed twice weekly.

Effectiveness and safety assessment. Tumour growth inhibition (TGI) and tumour growth delay time (T-C) were calculated, in order to assess the response of the tumours to the agents. TGI was calculated using the following formula: TGI $(\%)=[(\mathrm{DVc}-\mathrm{DVe}) / \mathrm{DVc}] \times 100 \%$, in which DVc is the difference between the final and initial tumour volumes of the blank control group, and DVe represents the change in tumour volume in each 
Table II. Dose regimen.

\begin{tabular}{lcccc}
\hline Group & $\mathrm{n}$ & Dosage $(\mathrm{mg} / \mathrm{kg})$ & Route & Administration time \\
\hline Blank control $^{\mathrm{a}}$ & 5 & - & Intratumoural injection & Q2Dx4 \\
VEGI74 & 5 & 5 & Intratumoural injection & Q2Dx4 \\
V7 & 5 & 5 & Intratumoural injection & Q2Dx4 \\
V8 & 5 & 5 & Intratumoural injection & Q2Dx4 \\
\hline
\end{tabular}

aPBS was used as a blank control. VEGI, vascular endothelial growth inhibitor.
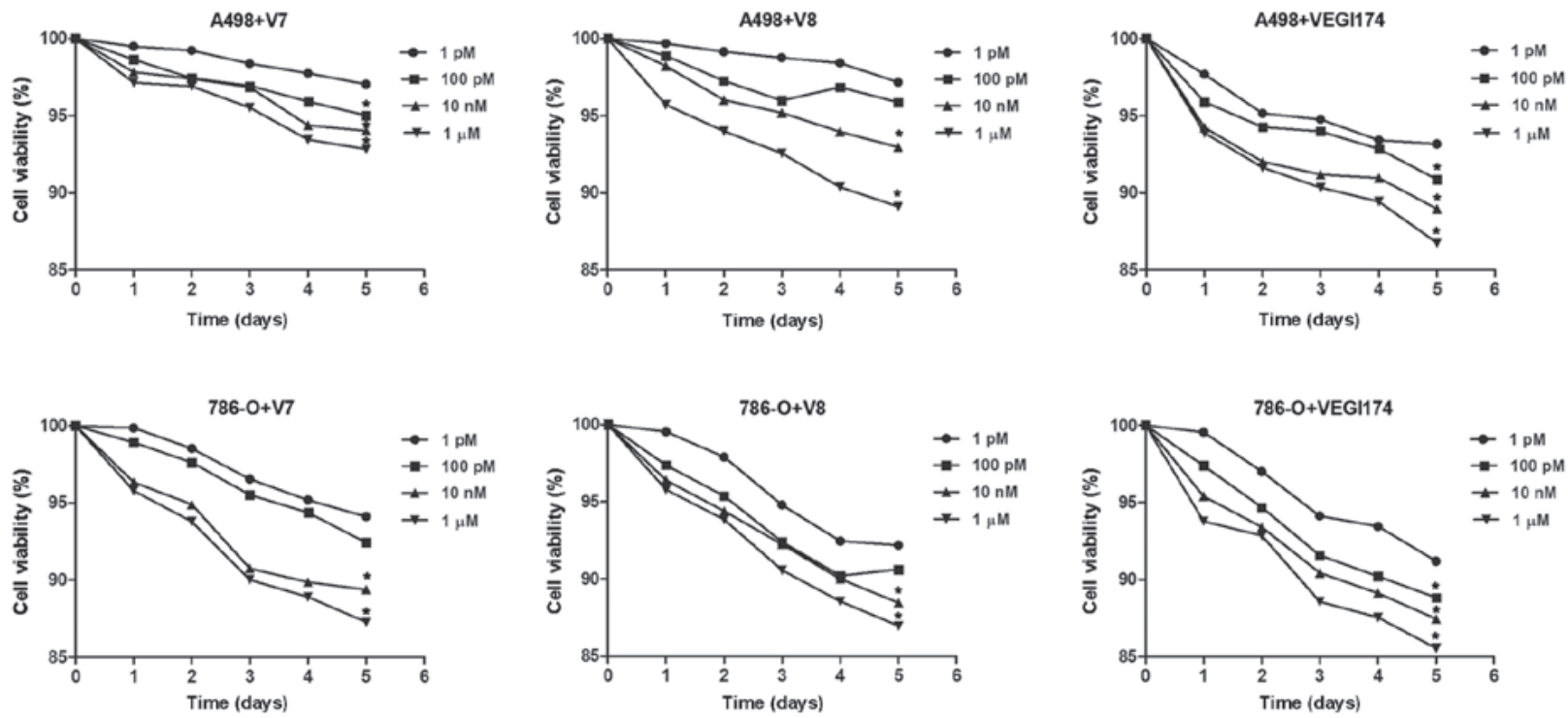

Figure 2. Effects of VEGI174 protein and V7 and V8 peptides on the proliferation of A498 and 786-O cells in vitro. Cell proliferation was inhibited following treatment with VEGI174, V7 and V8 at concentrations of 1 and $100 \mathrm{pM}, 10 \mathrm{nM}$ and $1 \mu \mathrm{M}$ in both cell lines. "P<0.05 vs. $1 \mathrm{pM}$. There was no significant difference in the inhibitory effects among the VEGI174-, V7- and V8-treated groups ( $>0.05)$. Proliferation was assessed by Cell Counting Kit-8. VEGI174, vascular endothelial growth inhibitor 174 .

agent-treated group. T-C refers to the difference in time (days) required for a tumour to reach a certain volume between the implanted tumour of a treatment group and that of the control group; $\mathrm{T}$ is the number of days required for the treatment group to reach a specific tumour volume, and $\mathrm{C}$ represents the number of days required for the control group to reach the same value.

Mouse behaviour, including temperament, appetite, activity, body weight changes and cases of mortality were recorded, in order to conduct a safety evaluation.

Statistical analysis. All statistical analyses were performed using SPSS software (version 20.0; IBM Corp., Armonk, NY, USA). The measured data (three replicates) are presented as the means \pm standard deviation. One-way analysis of variance and a least-significant difference multiple comparisons test were used to analyse the equality of the means among three or more groups. $\mathrm{P}<0.05$ was considered to indicate a statistically significant difference.

\section{Results}

VEGI174, V7 and V8 inhibit the proliferation of RCC cells in vitro. Viability of A498 and 786-O cells was continuously monitored for 5 days following treatment with the VEGI174 protein and the V7 and V8 peptides. Cell activity of the blank control group was set as the baseline. Compared with the blank control group, proliferation was inhibited following treatment with VEGI174, V7 and V8 at concentrations of 1 and $100 \mathrm{pM}$, $10 \mathrm{nM}$ and $1 \mu \mathrm{M}$ in both cell lines (Fig. 2). The inhibitory effects of treatment on RCC cells exhibited a dose-dependent effect in vitro; however, the inhibitory effects among the VEGI174-, V7- and V8-treated groups showed no significant differences $(\mathrm{P}>0.05)$.

VEGI174, V7 and V8 inhibit RCC cell migration and invasion in vitro. The present study used the xCELLigence system to investigate whether the VEGI174 protein and V7 and V8 peptides were involved in the regulation of RCC cell migration and invasion. These assays revealed that VEGI174, V7 and V8 significantly inhibited the migration and invasion of A498 cells compared with the control group at concentrations of $10 \mathrm{nM}$ and $1 \mu \mathrm{M}(\mathrm{P}<0.001$; Fig. 3). Inhibition of cell migration and invasion exhibited dose- and time-dependent effects. As the treatment concentration increased, the inhibitory effect became more obvious. In addition, cell migration and invasion were more notably affected after $\geq 24 \mathrm{~h}$ of treatment. 

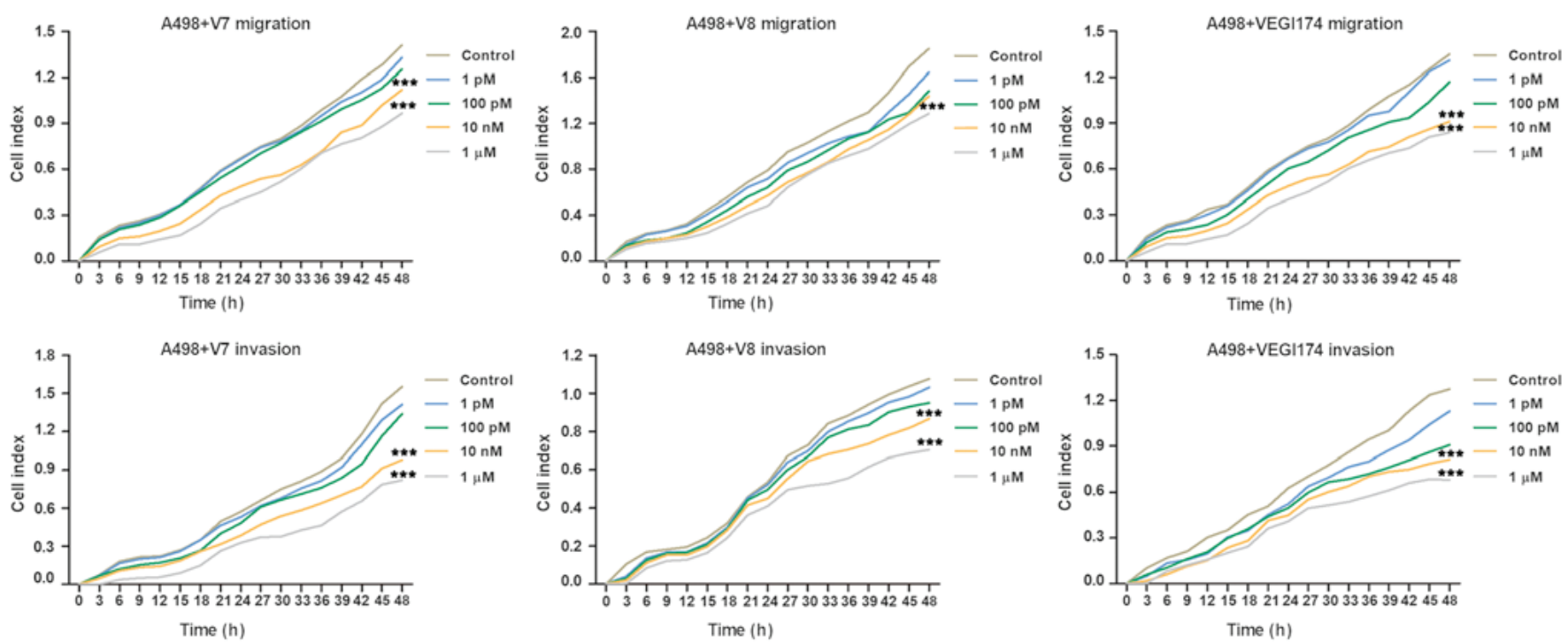

Figure 3. Cell migration and invasion of A498 cells treated with VEGI174 protein and V7 and V8 peptides. VEGI174, V7 and V8 significantly inhibited the migration and invasion of A498 cells at concentrations of $10 \mathrm{nM}$ and $1 \mu \mathrm{M}$. ${ }^{* * *} \mathrm{P}<0.001$ vs. the control group. VEGI174, vascular endothelial growth inhibitor 174 .
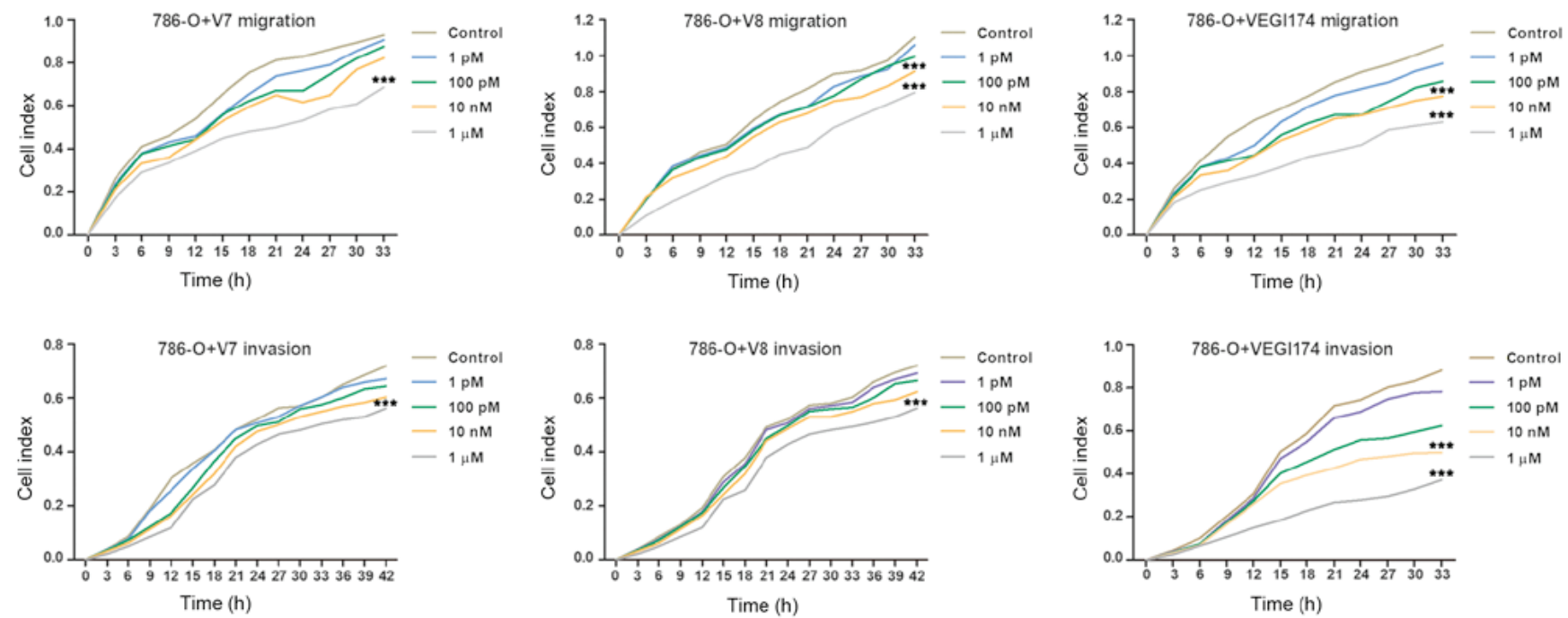

Figure 4. Cell migration and invasion of 786-O cells treated with VEGI174 protein and V7 and V8 peptides. VEGI174, V7 and V8 significantly inhibited the migration and invasion of A498 cells at concentrations of $10 \mathrm{nM}$ and $1 \mu \mathrm{M}$. ${ }^{* * * *} \mathrm{P}<0.001$ vs. the control group. VEGI174, vascular endothelial growth inhibitor 174 .

Conversely, no significant differences were observed in the inhibitory effects among the VEGI174-, V7- and V8-treated groups.

Consistently, treatment with the VEGI174 protein and V7 and V8 peptides significantly inhibited the migration and invasion of 786-O cells compared with in the control group at concentrations of $10 \mathrm{nM}$ and $1 \mu \mathrm{M}(\mathrm{P}<0.001$; Fig. 4). Inhibition of cell migration and invasion exhibited dose- and time-dependent effects. Notably, cell migration and invasion were more obviously affected after $\geq 24 \mathrm{~h}$ of treatment. These findings suggested that the V7 and V8 peptides may inhibit RCC cell migration and invasion, as well as VEGI174 protein, in vitro.

VEGII74, V7 and V8 suppress A498 xenograft growth in vivo. NOD/SCID mice were used to establish A498 xenografts. The effects of VEGI174, V7 and V8 were determined on A498 xenograft tumour growth over an 8-day (Q2Dx4) period (Fig. 5). Growth inhibition was observed in the VEGI174-, V7- and V8-treated groups compared with in the blank control group (Table III). The final tumour volume in the VEGI174-treated group was significantly smaller than that in the control group $(\mathrm{P}<0.05)$. The TGI of the VEGI174-treated group was $71 \%$, which was higher than in the V7- (20\%) and V8-treated (31\%) groups. In A498 xenografts, for T-C analysis, the average tumour volume was set at $350 \mathrm{~mm}^{3}$. The T-C values of the VEGI174-, V7- and V8-treated groups were 5, 1 and 3 days, respectively (Table III). There was no significant loss in body weight and no cases of mortality in all mice groups (Fig. 6A). The mice had a good temperament and appetite, and exhibited normal activity levels. Overall, VEGI174, V7 and V8 treatments were well tolerated and safe.

VEGI174, V7 and V8 suppress 786-O xenograft growth in vivo. A second xenograft study was performed using 786-O 
Table III. TV, TGI and T-C following treatment with VEGI174, V7 and V8 in A498 xenografts.

\begin{tabular}{|c|c|c|c|c|c|}
\hline Group & T-C (days) & TV before treatment $\left(\mathrm{mm}^{3}\right)$ & TV after final treatment $\left(\mathrm{mm}^{3}\right)$ & TGI $(\%)$ & P-value ${ }^{a}$ \\
\hline Blank control & - & $187 \pm 28$ & $838 \pm 50$ & - & - \\
\hline VEGI174 & 5 & $192 \pm 9$ & $383 \pm 30$ & 71 & 0.006 \\
\hline V7 & 1 & $196 \pm 12$ & $672 \pm 43$ & 20 & 0.685 \\
\hline V8 & 3 & $196 \pm 14$ & $595 \pm 50$ & 31 & 0.501 \\
\hline
\end{tabular}

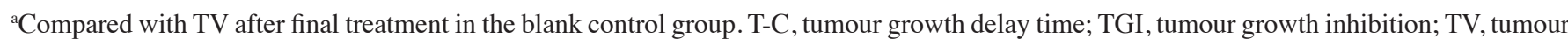
volume.
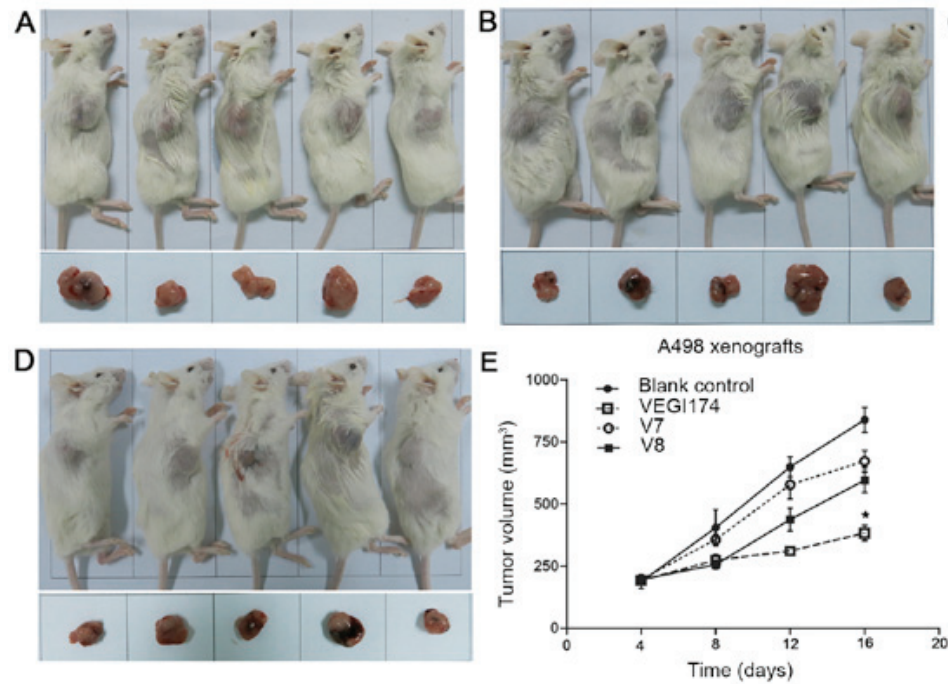

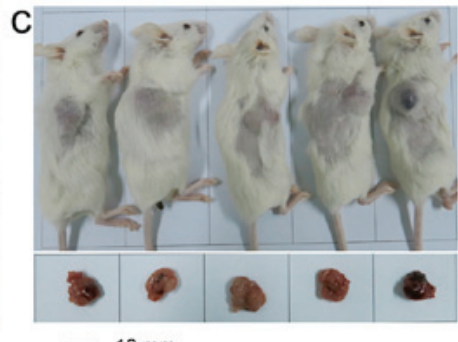

$-10 \mathrm{~mm}$

Figure 5. Tumour volume alterations in A498 xenografts. Once the implanted tumours grew to $\sim 190 \mathrm{~mm}^{3}$ in size, mice were randomised into the blank control group and treatment groups ( $\mathrm{n}=5$ mice/group). VEGI174, V7 and V8 were administered as single agents, and PBS was added as a blank control via intratumoural injection every other day for a total of four doses. (A) Blank control group; (B) VEGI174-treated group; (C) V7-treated group; and (D) V8-treated group mice. (E) The final tumour volume of the VEGI174-treated group was significantly smaller than that of the control group. "P<0.05 vs. the control group. VEGI174, vascular endothelial growth inhibitor 174.

A

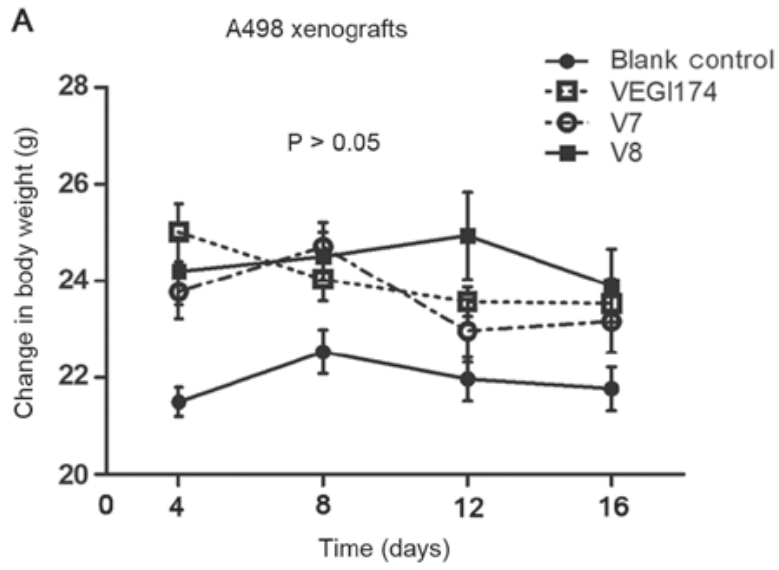

B

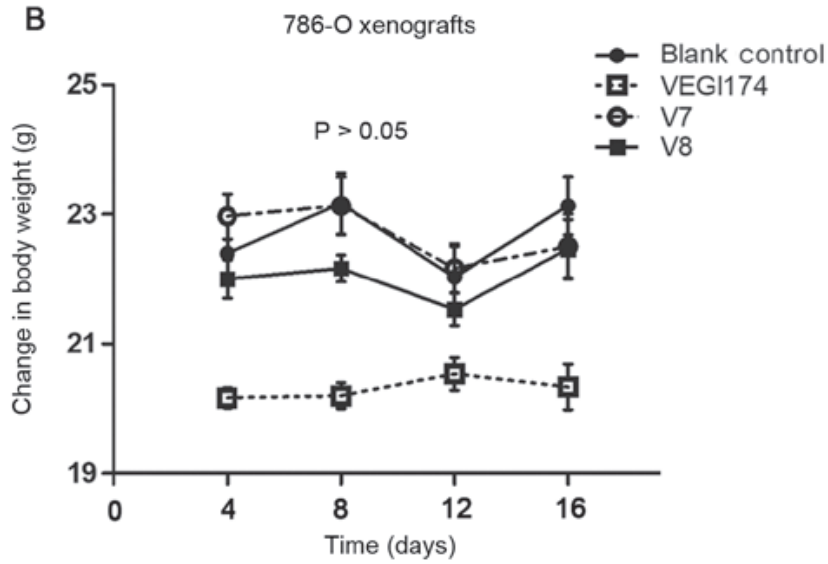

Figure 6. (A) Body weight alterations in the A498 xenograft mice. At the end of the study, the average weight of the blank control group was $21.7 \pm 2.1 \mathrm{~g}$, and the average weights for the VEGI174-, V7- and V8-treated groups were $23.9 \pm 0.9,23.3 \pm 0.6$ and $23.9 \pm 0.7 \mathrm{~g}$, respectively (P>0.05). (B) Body weight alterations in the 786-O xenograft mice. At the end of the study, the average weight of the blank control group was $23.2 \pm 0.7 \mathrm{~g}$, and the average weights for the VEGI174-, V7- and V8-treated groups were 20.3 $\pm 0.4,22.6 \pm 0.6$ and $22.2 \pm 0.7 \mathrm{~g}$, respectively ( $\mathrm{P}>0.05)$. VEGI174, vascular endothelial growth inhibitor 174 .

cells to determine the effects of VEGI174, V7 and V8 on tumour growth over an 8-day (Q2Dx4) period (Fig. 7). TGI was also observed in the VEGI174-, V7- and V8-treated groups; however, the rates were not significant compared with in the blank control-treated group (Table IV). The TGI rates of the VEGI174-, V7- and V8-treated groups were 34, 
Table IV. TV, TGI and T-C following treatment with VEGI174, V7 and V8 in 786-O xenografts.

\begin{tabular}{lcccc}
\hline Group & T-C (days) & TV before treatment $\left(\mathrm{mm}^{3}\right)$ & TV after final treatment $\left(\mathrm{mm}^{3}\right)$ & TGI $(\%)^{\text {P-value }}$ \\
\hline Blank control & - & $129 \pm 22$ & $447 \pm 30$ & - \\
VEGI174 & 3.5 & $130 \pm 13$ & $341 \pm 35$ & 0.171 \\
V7 & 1 & $129 \pm 17$ & $364 \pm 45$ & 0.547 \\
V8 & 1.5 & $127 \pm 17$ & $345 \pm 40$ & 26 \\
\hline
\end{tabular}

${ }^{\mathrm{a} C o m p a r e d ~ w i t h ~ t h e ~ T V ~ a f t e r ~ f i n a l ~ t r e a t m e n t ~ i n ~ t h e ~ b l a n k ~ c o n t r o l ~ g r o u p . ~ T-C, ~ t u m o u r ~ g r o w t h ~ d e l a y ~ t i m e ; ~ T G I, ~ t u m o u r ~ g r o w t h ~ i n h i b i t i o n ; ~ T V, ~}$ tumour volume.
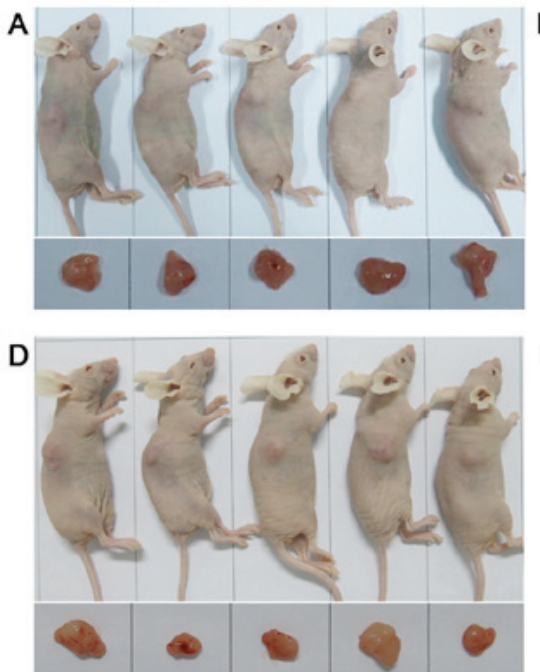

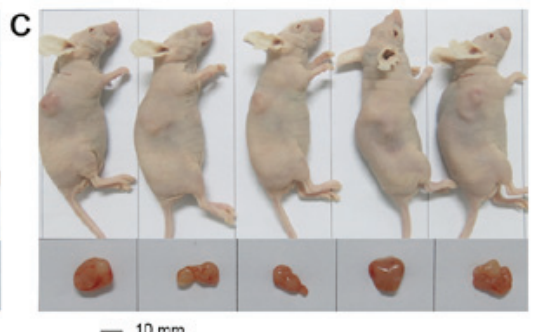

$-10 \mathrm{~mm}$

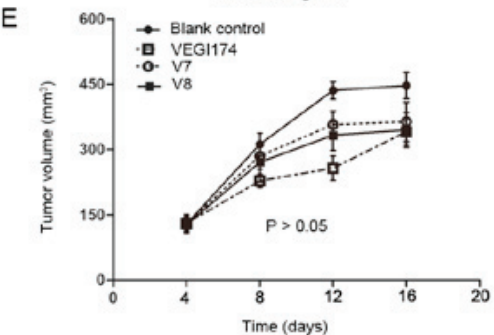

Figure 7. Tumour volume alterations in the 786-O xenograft mice. Once the implanted tumours had grown to $\sim 130 \mathrm{~mm}^{3}$ in size, mice were randomised into the blank control group and treatment groups ( $\mathrm{n}=5$ mice/group). VEGI174, V7 and V8 were administered as single agents, and PBS was used as a blank control via intratumoural injection every other day for a total of four doses. (A) Blank control group; (B) VEGI174-treated group; (C) V7-treated group; and (D) V8-treated group mice. (E) The final tumour volume of the VEGI174-, V7- and V8-treated groups was smaller than that of the control group; however, this was not statistically significant $(\mathrm{P}>0.05)$. VEGI 174, vascular endothelial growth inhibitor 174.

26 and $31 \%$, respectively. In 786-O xenografts, for T-C analysis, the average tumour volume was set at $300 \mathrm{~mm}^{3}$. The T-C values of the VEGI174-, V7- and V8-treated groups were 3.5, 1 and 1.5 days, respectively (Table IV). The body weights of all 786-O xenograft-implanted mice were stable, and there were no agent-related cases of mortality (Fig. 6B). The mice had a good temperament and appetite, and exhibited normal activity levels during the experimental period. These findings indicated that VEGI174, V7 and V8 were well tolerated and safe in the 786-O xenograft mouse models.

\section{Discussion}

VEGI174 is a cytokine that belongs to the TNF ligand family. It is abundantly expressed in endothelial cells and is a ligand for the TNF receptor superfamily member (TNFRSF) 25 receptor and the TNFRSF21/death receptor 6 decoy receptor $(30,31)$. Numerous studies have investigated its expression and biological functions in cancer, and have demonstrated that VEGI expression is absent in the tumour vasculature in various types of cancer $(32,33)$. Parr et al (18) reported that VEGI is aberrantly expressed in breast cancer and has prognostic relevance. Patients with breast cancer with low expression levels of VEGI have a poorer prognosis than those with high VEGI expression. Our previous study also observed a decrease in the expression of VEGI in RCC tissues (22). In addition, Chew et al (14) demonstrated that overexpression of VEGI abrogates xenograft tumour progression by reducing tumour growth rate and microvessel density. It has also been demonstrated that overexpression of VEGI inhibits RCC cell motility, EMT, vascular endothelial tube formation and tumour growth (21-24). Furthermore, VEGI participates in regulating the biological functions of several tumour cell lines, including breast carcinoma (MCF-7), cervical carcinoma (HeLa) and myeloid tumour (U-937 and ML-1a) cell lines $(34,35)$.

Notably, Hou et al (36) reported that systemic administration of recombinant human VEGI192 protein gave rise to a marked inhibition of tumour growth and an increased survival time in a Lewis lung carcinoma murine tumour model. VEGI174 is one of three alternatively spliced isoforms of VEGI. It is important to further demonstrate how VEGI174 protein and its peptide fragments function in RCC. Among the VEGI174 functional domains, our prestudies verified that the inhibitory effects produced by the V7 and V8 domains are more significant than those produced by the other functional domains. In the present study, VEGI174 and its functional 
domain peptides (V7 and V8) were biosynthesized, and their effects on RCC proliferation, migration and invasion were detected.

The cell viability of A498 and 786-O cell lines was inhibited following treatment with various concentrations of VEGI174, V7 and V8. In addition, the xCELLigence system clearly monitored A498 and 786-O cell migration and invasion. The data confirmed that VEGI174, V7 and V8 significantly regulated the cell migration and invasion of A498 and 786-O cells in vitro. Furthermore, inhibition of cell proliferation, migration and invasion exhibited dose- and time-dependent effects, which require further exploration.

The in vivo study provided support for the ability of VEGI174, V7 and V8 to inhibit RCC growth. TGI was observed in the A498 and 786-O xenograft models. In the A498 xenograft mice, the TGI rates of the VEGI174-, V7- and V8-treated groups were 71, 20 and 31\%, respectively. The T-C values of the VEGI174-, V7- and V8-treated groups were 5, 1 and 3 days, respectively. In the 786-O xenografts, the TGI rates of the VEGI174-, V7- and V8-treated groups were 34, 26 and $31 \%$, respectively. The T-C values of the VEGI174-, V7- and V8-treated groups were 3.5, 1 and 1.5 days, respectively. These findings indicated that the V7 and V8 peptides were slightly inferior to the VEGI174 protein in terms of antitumour activity. The V7 and V8 peptides are only parts of the VEGI174 protein, and their spatial structures and biological functions are different; therefore, these features require more intensive study. Any drug resulting in a TGI of $\geq 58 \%$ (the National Cancer Institute standard criterion for antitumour activity) is considered a valid anticancer agent (37). VEGI174, V7 and V8 have exerted potential antitumour effects in vivo. Notably, the V7 and V8 peptides inhibited RCC cell proliferation, migration and invasion as well as the VEGI174 protein did in vitro. These data strongly support the fact that V7 and V8 are important functional domains of VEGI174.

The safety and tolerance of the three agents were also evaluated in vivo. Mouse behaviour, including temperament, appetite, activity, body weight gain/loss and mortality, were recorded. The mice in all groups had no abnormal appearance or behaviour, all of the mice survived, and their body weights were stable. These results preliminarily demonstrated that VEGI174, V7 and V8 were safe and well tolerated.

The VEGI174 protein and its domain peptides (V7 and V8) exhibited inhibitory effects on RCC proliferation, migration and invasion; however, the exact mechanism remains unclear. Zhang et al (38) reported that VEGF expression could be suppressed by VEGI-stimulated TNF superfamily member 15 activation of the Jun N-terminal kinase-GATA binding protein 3 signalling pathway. Qi et al (39) reported that VEGI inhibits vasculogenesis by regulating the relative levels of membrane-bound and soluble isoforms of VEGF receptor-1. Overall, these data suggested that the VEGI174 protein and its domain peptides may negatively regulate the VEGF pathway, in order to inhibit tumour growth. Our previous study also demonstrated that there was an inverse correlation between VEGI174 and microvessel density (22). Notably, in the present study, it was demonstrated that the VEGI174 protein and V7 and V8 peptides inhibited the proliferation, migration and invasion of A498 and 786-O cells in vitro. These data indicated that VEGI174, and V7 and V8 peptides may directly interact with tumour cells and regulate cellular functions. In addition, the mechanism underlying the inhibitory effects of VEGI174 on tumour growth may not be limited to the VEGF pathway but may involve other signalling pathways; this should be analysed in future research.

In conclusion, based on the overall antitumour activity of VEGI174, V7 and V8 in RCC, V7 and V8 may be considered important functional domains of VEGI174. The differences in the secondary and tertiary structures between the V7 and V8 peptides, and the VEGI174 protein, should be analysed in future studies, in order to improve antitumour effects and provide information for novel drug development. In addition, the regulatory mechanisms of VEGI174 and the V7 and V8 peptides on RCC cell functions should be carefully elucidated.

\section{Acknowledgements}

Not applicable.

\section{Funding}

The present study was supported by the National Natural Science Foundation of China (grant no. 81372738).

\section{Availability of data and materials}

The datasets used and/or analysed during the current study are available from the corresponding author on reasonable request.

\section{Authors' contributions}

NZ and YY were involved in study conception and design. YY, LY and KG developed the methodology. QZ, BAH, TZL, XXT and YPJ were involved in data acquisition and analysis. NZ, QZ, BAH and LY were involved in writing, reviewing and/or revising the manuscript. XXT and LY provided technical and material support. KG and YY provided study supervision.

\section{Ethics approval and consent to participate}

The present study was approved by the ethics committee of Beijing Institute for Cancer Research. The animal studies were approved by the ethics committee of Beijing Institute for Cancer Research, and IACUC of Crown Bioscience. Procedures related to animal handling, care, and treatment in this study were performed according to the guidelines approved by the IACUC of Crown Bioscience and following the guidance of the Association for Assessment and Accreditation of Laboratory Animal Care.

\section{Patient consent for publication}

Not applicable.

\section{Competing interests}

The authors declare that they have no competing interests. 


\section{References}

1. Siegel RL, Miller KD and Jemal A: Cancer statistics, 2016. CA Cancer J Clin 66: 7-30, 2016.

2. Russo P: Renal cell carcinoma: Presentation, staging, and surgical treatment. Semin Oncol 27: 160-176, 2000.

3. Liu L, Zhang W, Qi X, Li H, Yu J, Wei S, Hao X and Ren X: Randomized study of autologous cytokine-induced killer cell immunotherapy in metastatic renal carcinoma. Clin Cancer Res 18: 1751-1759, 2012

4. Jonasch E and Motzer RJ: Ten years of progress in renal cell carcinoma. J Natl Compr Canc Netw 10: 690-693, 2012.

5. Barata PC and Rini BI: Treatment of renal cell carcinoma: Current status and future directions. CA Cancer J Clin 67: 507-524, 2017.

6. Bedke J, Gauler T, Grünwald V, Hegele A, Herrmann E, Hinz S, Janssen J, Schmitz S, Schostak M, Tesch H, et al: Systemic therapy in metastatic renal cell carcinoma. World J Urol 35: 179-188, 2017.

7. Vachhani $\mathrm{P}$ and George S: VEGF inhibitors in renal cell carcinoma. Clin Adv Hematol Oncol 14: 1016-1028, 2016.

8. Posadas EM, Limvorasak S and Figlin RA: Targeted therapies for renal cell carcinoma. Nat Rev Nephrol 13: 496-511, 2017.

9. Rini BI and Atkins MB: Resistance to targeted therapy in renal-cell carcinoma. Lancet Oncol 10: 992-1000, 2009.

10. Haddad AQ and Margulis V: Tumour and patient factors in renal cell carcinoma-towards personalized therapy. Nat Rev Urol 12 253-262, 2015.

11. Hsieh JJ, Manley BJ, Khan N, Gao J, Carlo MI and Cheng EH: Overcome tumor heterogeneity-imposed therapeutic barriers through convergent genomic biomarker discovery: A braided cancer river model of kidney cancer. Semin Cell Dev Biol 64: 98-106, 2017

12. Tan KB, Harrop J, Reddy M, Young P, Terrett J, Emery J, Moore G and Truneh A: Characterization of a novel TNF-like ligand and recently described TNF ligand and TNF receptor superfamily genes and their constitutive and inducible expression in hematopoietic and non-hematopoietic cells. Gene 204: 35-46, 1997.

13. Zhai Y, Yu J, Iruela-Arispe L, Huang WQ, Wang Z, Hayes AJ, Lu J, Jiang G, Rojas L, Lippman ME, et al: Inhibition of angiogenesis and breast cancer xenograft tumor growth by VEGI, a novel cytokine of the TNF superfamily. Int J Cancer 82: 131-136, 1999.

14. Chew LJ, Pan H, Yu J, Tian S, Huang WQ, Zhang JY, Pang S and Li LY: A novel secreted splice variant of vascular endothelial cell growth inhibitor. FASEB J 16: 742-744, 2002.

15. Zhang N, Sanders AJ, Ye L and Jiang WG: Vascular endothelial growth inhibitor in human cancer (Review). Int J Mol Med 24 3-8, 2009.

16. Zhai Y, Ni J, Jiang GW, Lu J, Xing L, Lincoln C, Carter KC, Janat F, Kozak D, Xu S, et al: VEGI, a novel cytokine of the tumor necrosis factor family, is an angiogenesis inhibitor that suppresses the growth of colon carcinomas in vivo. FASEB J 13: 181-189, 1999.

17. Liang PH, Tian F, Lu Y, Duan B, Stolz DB and Li LY: Vascular endothelial growth inhibitor (VEGI; TNFSF15) inhibits bone marrow-derived endothelial progenitor cell incorporation into Lewis lung carcinoma tumors. Angiogenesis 14: 61-68, 2011.

18. Parr C, Gan CH, Watkins $\mathrm{G}$ and Jiang WG: Reduced vascular endothelial growth inhibitor (VEGI) expression is associated with poor prognosis in breast cancer patients. Angiogenesis 9: 73-81, 2006.

19. Zhang N, Sanders AJ, Ye L, Kynaston HG and Jiang WG: Vascular endothelial growth inhibitor, expression in human prostate cancer tissue and the impact on adhesion and migration of prostate cancer cells in vitro. Int J Oncol 35: 1473-1480, 2009.

20. Zhang N, Sanders AJ, Ye L, Kynaston HG and Jiang WG: Expression of vascular endothelial growth inhibitor (VEGI) in human urothelial cancer of the bladder and its effects on the adhesion and migration of bladder cancer cells in vitro. Anticancer Res 30: 87-95, 2010.

21. Zhang N, Wu P, Shayiremu D, Wu L, Shan H, Ye L, Zhao X, Cai J, Jiang WG, Gong K, et al: Suppression of renal cell carcinoma growth in vivo by forced expression of vascular endothelial growth inhibitor. Int J Oncol 42: 1664-1673, 2013.

22. Wu L, Li X, Ye L, Shayiremu D, Deng X, Zhang X, Jiang W, Yang Y, Gong K and Zhang N: Vascular endothelial growth inhibitor 174 is a negative regulator of aggressiveness and microvascular density in human clear cell renal cell carcinoma. Anticancer Res 34: 715-722, 2014.
23. Zhang N, Hong B, Lian W, Zhou C, Chen S, Du X, Deng X, Duoerkun S, Li Q, Yang Y, et al: Vascular endothelial growth inhibitor 174 and its functional domains inhibit epithelial-mesenchymal transition in renal cell carcinoma cells in vitro. Int J Mol Med 40: 569-575, 2017.

24. Zhao Q, Liu T, Hong B, Wang F, Zhou C, Du X, Chen S, Deng X, Duoerkun S, Li Q, et al: Vascular Endothelial Growth Inhibitor, a Cytokine of the Tumor Necrosis Factor Family, is Associated With Epithelial-Mesenchymal Transition in Renal Cell Carcinoma. Appl Immunohistochem Mol Morphol, 2017.

25. Szulcek R, Bogaard HJ and van Nieuw Amerongen GP: Electric cell-substrate impedance sensing for the quantification of endothelial proliferation, barrier function, and motility. $\mathrm{J}$ Vis $\operatorname{Exp} 85$ : e51300, 2014

26. Chen SW, Yang JM, Yang JH, Yang SJ and Wang JS: A computational modeling and analysis in cell biological dynamics using electric cell-substrate impedance sensing (ECIS). Biosens Bioelectron 33: 196-203, 2012.

27. Dowling CM, Herranz Ors C and Kiely PA: Using real-time impedance-based assays to monitor the effects of fibroblast-derived media on the adhesion, proliferation, migration and invasion of colon cancer cells. Biosci Rep 34: 34, 2014.

28. Stefanowicz-Hajduk J, Adamska A, Bartoszewski R and Ochocka JR: Reuse of E-plate cell sensor arrays in the xCELLigence Real-Time Cell Analyzer. Biotechniques 61: 117-122, 2016.

29. Kho D, MacDonald C, Johnson R, Unsworth CP, O'Carroll SJ, du Mez E, Angel CE and Graham ES: Application of xCELLigence RTCA Biosensor Technology for Revealing the Profile and Window of Drug Responsiveness in Real Time. Biosensors (Basel) 5: 199-222, 2015.

30. Migone TS, Zhang J, Luo X, Zhuang L, Chen C, Hu B, Hong JS, Perry JW, Chen SF, Zhou JX, et al: TL1A is a TNF-like ligand for DR3 and TR6/DcR3 and functions as a T cell costimulator. Immunity 16: 479-492, 2002.

31. Tian F, Grimaldo S, Fujita M, Cutts J, Vujanovic NL and Li LY: The endothelial cell-produced antiangiogenic cytokine vascular endothelial growth inhibitor induces dendritic cell maturation. J Immunol 179: 3742-3751, 2007.

32. Zhou J, Yang Z, Tsuji T, Gong J, Xie J, Chen C, Li W, Amar S and Luo Z: LITAF and TNFSF15, two downstream targets of AMPK, exert inhibitory effects on tumor growth. Oncogene 30: 1892-1900, 2011

33. Deng W, Gu X, Lu Y, Gu C, Zheng Y, Zhang Z, Chen L, Yao Z and Li LY: Down-modulation of TNFSF15 in ovarian cancer by VEGF and MCP-1 is a pre-requisite for tumor neovascularization. Angiogenesis 15: 71-85, 2012.

34. Xiao Q,Hsu CY, Chen H, Ma X,Xu J and Lee JM: Characterization of cis-regulatory elements of the vascular endothelial growth inhibitor gene promoter. Biochem J 388: 913-920, 2005.

35. Haridas V, Shrivastava A, Su J, Yu GL, Ni J, Liu D, Chen SF, Ni Y, Ruben SM, Gentz R, et al: VEGI, a new member of the TNF family activates nuclear factor-kappa B and c-Jun $\mathrm{N}$-terminal kinase and modulates cell growth. Oncogene 18: 6496-6504, 1999.

36. Hou W, Medynski D, Wu S, Lin X and Li LY: VEGI-192, a new isoform of TNFSF15, specifically eliminates tumor vascular endothelial cells and suppresses tumor growth. Clin Cancer Res 11: 5595-5602, 2005 .

37. Meyer CJ, Krauth M, Wick MJ, Shay JW, Gellert G, De Brabander JK, Northcote PT, Miller JH and Peloruside A: Peloruside A Inhibits Growth of Human Lung and Breast Tumor Xenografts in an Athymic nu/nu Mouse Model. Mol Cancer Ther 14: 1816-1823, 2015.

38. Zhang K, Cai HX, Gao S, Yang GL, Deng HT, Xu GC, Han J, Zhang QZ and Li LY: TNFSF15 suppresses VEGF production in endothelial cells by stimulating miR-29b expression via activation of JNK-GATA3 signals. Oncotarget 7: 69436-69449, 2016.

39. Qi JW, Qin TT, Xu LX, Zhang K, Yang GL, Li J, Xiao HY, Zhang ZS and Li LY: TNFSF15 inhibits vasculogenesis by regulating relative levels of membrane-bound and soluble isoforms of VEGF receptor 1. Proc Natl Acad Sci USA 110: 13863-13868, 2013. 